\title{
CHEMICAL CHARACTERIZATION OF THE SURFACE SITES OF COAL
}

\author{
Technical Progress Report for the Period \\ July - September, 1989 \\ Frederick M. Fowkes \\ with \\ Keith Kardos, \\ Floyd L. Riddle, Jr. , \\ and \\ David A. Cole. \\ Department of Chemistry \\ Lehigh University \\ Bethlehem, PA 18015
}

Recaivad by UST7

OCT $\bigcirc 91990$

August 1990

PREPARED FOR THE UNITED STATES

DEPARTMENT OF ENERGY

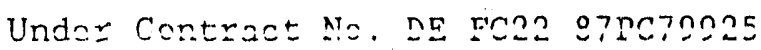

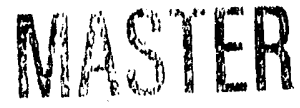


This report was prepared as an account of work sponsored by the United States Government. Neither the United States, nor the United States. Department of Energy, nor any of their employees, nor any of their contractors, subcontractors; or their employees, makes any warranty, expressed or implied, or assumes any legal liability or xesponsibility for the accuracy, completeness, or usefulness of any information, apparatus, product or process disclosed, or represents that its use would not infringe privately owned rights.

\section{DISCLAIMER}

This report was prepared as an account of work sponsored by an agen y of the United States Government. Neither the United States Government nor any agency thereof, nor any of their employees, makes any warranty, express or implied, or assumes any legal liability or responsibility for the accuracy, completeness, or usefulness of any information, apparatus, product, or process disclosed, or represents that its use would not infringe privately owned rights. Reference herein to any specific commercial product, process, or service by trade name, irademark, manufacturer, or otherwise does not necessarily constitute or imply its endorsement, recommendation, or favoring by the United States Government or any agency thereof. The views and opinions of authors expressed herein do not necessarily state or reflect those of the United States Government or any agency thereof. 


\section{OBJECTIVES AND SCOPE OF WORK}

We propose to do experimental'studies in four related areas concorning the acid-base properties of coal surfaces; 1) develop high precision flow microcalorimetric methods for determining the concentrations and strengths of the acidic and basic surface sites of coal powders; 2) develop photo-acoustic FTIR and solid-state NMR spectral shift techniques for determination of the concentrations and strengths of acidic and basic surface sites of coal

powders; 3) determine the concentrations and strengths of the acidic and basic surface sices of some of the well-characterized coal samples from Argonne National Labs, comparing the coal samples before and after demineralization treatments with $\mathrm{HCl}$ and $\mathrm{HF} ; 4$ ) study the effects of surface acidity and basicity on the coal/water interface. with emphasis on the role of interfacial acid-base interactions in the adsorption of ions, surfactants and coal/water slurry stabilizers.

A practical application of the new measurements of the reactions of surface sites will be to determine the acid-base contributions to adsorption of ions and of surfactants from aqueous media onto coal, where more than just hydrophobic bonds and electrostatic attractions are involved. An example is the adsorption of phosphates, which adsorb more strongly than sulfates. 


\section{TECHNICAL PROGRESS}

The Department of Chemistry at Lehigh University participates annually in the NSF REU (Research Experience for Undergraduate students) program in which undergraduate students work directly with established research. During the summer of 1989 we were fortunate to have Keith Kardos join us on this project. We chose to have Keith work on measuring the surface acidity and basicity of coals by flow microcalorimetry. Our previous experience with this technique lead us to believe that the work, although quite challenging, could be completed for one or two coals during his sumer internship. Much to our dismay much of the summer was spent tracking down and fixing several problems which arose in our Microscal flow microc lorimeter. However by the end of his stay, Keith understood not only the routine problems one encounters with this technique such as sample preparation but knew quite intimately the electronics of the Microscal. as much of the instrument was rebuilt during this time. All in all Keith felt that he learn many valuable lessons during the summer and has decided to attend Lehigh University in the fall of 1990 to work towards a Ph.D. in organic chemistry. This report is based on the seminar which Keith presented to the Chemistry Department, August 1989.

The goal of this research effort was to begin characterizing the acidic and basic sites on the surface coal by flow microcalorimetry. The premise of the experiment is that exothermic heats of interaction between organic acids or bases in neutral solvents and acidic and basic surface sites of solids obey the Drago $C$ and $E$ equation (1)

$$
-\Delta H^{a b}(k c a l / m o l e)=C_{A} C_{B}+E_{A} E_{B}
$$

The $E_{A}$ and $E_{B}$ terms correspond to the electrostatic character of the acid and base respectively and the $C_{A}$ and $C_{B}$ terms correspond to the comolant ohorantar of a particular substance. The C/E ratio is correlated with the hardness or 
softness of an acid or base. $\mathrm{C}_{\mathrm{A}} / \mathrm{E}_{\mathrm{A}}$ ratios for acids are generally less than one, and the smaller the $\mathrm{C} / \mathrm{E}$ ratio, the harder the acid while the larger the ratio, the softer the acid. $\mathrm{C}_{\mathrm{B}} / \mathrm{E}_{\mathrm{B}}$ ratios for bases are generally greater than one. Low ratios are indicative of hard bases such as the oxygen of carjonyl functional groups. High $\mathrm{C}_{\mathrm{B}} / \mathrm{E}_{\mathrm{B}}$ ratios correspond to soft bases such as sulfides. For example phenol $\left(\mathrm{C}_{\mathrm{A}} / \mathrm{E}_{\mathrm{A}}=0.10\right)$ is a harder acid than thiophenol $\left(C_{A} / E_{A}=0.2\right)$ and pyridine $\left(C_{B} / E_{B}=5.5\right)$ is a harder base than dimethyl sulfide $\left(C_{B} / E_{B}=21.7\right)$ but softer than ethyl acetate $\left(C_{B} / E_{B}=1.8\right)$. Knowing the molar heat of acid-base interaction one can estimate which surface functional groups of the coal have been titrated by the probe. If low heats are observed with an acidic probe such as phenol then the basic surface groups would be expected to be something similar to the aromatic structure of benzene $\left(-\Delta H^{a b}=2.16\right.$ $\mathrm{Kcal} / \mathrm{mole}$ for phenol-benzene interactions). If higher heats were obtained, then stronger basic surface groups such as pyridine would be suspected $\left(-\Delta \mathrm{H}^{\mathrm{ab}}=7.9 \mathrm{Kcal} / \mathrm{mole}\right.$ for phenol-pyridine interactions). From the measured heats of interaction one can make a reasonable estimate as to what functional groups are the most prevalent in the coal.

Enthalpies of acid-base interactions were measured using a Microscal flow calorimeter. The basic method of flow calorimeter involves two matched syringes and syringe pumps, one to deliver solvent and one to deliver a dilute solution ( $\approx 20$ millimolar) of acilic or basic probe molecule. By use of a two-way valve the pumps are alternated so that the probes may be adsorbed on to the coal and then desorbed from the coal and the heat of adsorption and desorption recorded. The system used included a computer interface which allowed all of the data acquisition and analysis to be done by computer. The amount of probe adsorbed or desorbed was monitured by a cuwn screali lý detector. 
The thermal response of the flow calorimeter was calibrated by generating a known amount of heat in the bed by placing a calibration cell containing a resistive wire in the sample bed. A coal sample is loaded and solvent is run over the bed until thermal equilibrium is obtained. A known voltage is applied across the resistive heating wire and the resulting heat is calculated by equation (2),

$$
\Delta \mathrm{H}(\text { milical })=\frac{V^{2} r t}{(\mathrm{R}+\mathrm{r}+0.21)^{2}} \times \frac{1000}{4.184}
$$

where $v$ is the applied voltage, $r$ is the resistance of the heating wire, $t$ is the time duration of heating, and $R$ is a variable resistance which controls the maximum heat generated. Once the thermal response (integrated signal intensity verses energy input) of the calorimeter is established, the heat of reaction can be calculated: Some of the problems associated with this calibration method are discussed in report DOE/PC/79925-11.

The moles of solute adsorbed is determined from the UV signal intensity and is calibrated by by-passing the bed and pumping the probe solution and solvent directly into the detector. These calibration curves are subtracted form the corresponding experimental curves. The calibration is necessary because there is an appreciable amount of diffusion when the solution front meets the solvent front and vice versa. A more detailed description of the experimental details of flow calorimetry can be found in our recent publication "Surface Chemistry of Coal by Flow Microcalorimetry", F. M. Fowkes, K. L. Jones, G. Li, and T. B. Lloyd, Energy \& Fuels 3, 97-105 (1989).

\section{Problems Encountered}

During this quarter many problems arose with the Microscal calorimeter. These problems included a noisy signal, 10w and crratic solutica and acincat flow rates, and drifting base lines. The noisy signal was of major concern as 
it. causes significant errors in integration. Steady flow rates are necessary because the flow rates modify the bed temperature and are used to determine the amount of solute adsorbed and desorbed. Based on our previous knowledge of the instrument, these problems were attributed to variations in sample packing in the bed. Several coals of various rank, ground and sieved to several mesh sizes were tried. None of these samples however yielded totally acceptable results.

The cause of the low and erratic flow rates was determined to be blockage of the outlet tube of the calorimeter and to a sliver of tubing which was accidentally cut from the inside of the inlet tubing. It was also found that coals ground and sieved to a mesh size -120 but +230 gave very constant flow rates, whereas finer grinding caused plugging of the bed.

The independence of the signal noise level with changes in sample type, size, and packing as well as testing the calorimeter with several types of glass fibers which were known to exhibit no effects due to packing lead us to search for the noise problem in the electronics of the instrument. The calorimeter detects heat by a change in voltage across the two thermistors arranged in a wheatstone bridge circuit. After much effort it was discovered that one of the four batteries which apply a constant voltage to the bridge was incapable of providing a constant voltage. Replacement of the batteries removed much of the signal noise. The potentioneters which are used to balance the wheatstone bridge were also replaced as it was found that the resistances were very position sensitive.

The cause of the drifting base lines was attributed to slight changes in the flow rate. This results from slight imperfections in the plungers and barrels of the syringes. Since those cmall imperfections are only noticaside at the highest sensitivities, the problem was not addressed further. 


\section{Results}

The acidic and basic probes that were used in this study were tert-butyl substituted phenols and pyridines. These probes were chosen since they have limited solubility in the coal and thus only the surface sites of the coal are characterized as described in detail in the foregoing reference. The coal used for the various trials was a low ash anthracite, PSOC 870 . The proximate and ultimate analysis if this coal is given in Table 1 . This coal was used in an attempt to replicate previous work done by Ken Jones in our laboratories. The results obtained are listed in Table 2. As it is shown in thi:s table our results did not agree within experimental error with those of Jones. Based on the limited number of measurements however, the accuracy of our data is uncertain. The current data suggests that the low ash anthracite coal used was not greatly functionalized. Based on the low molar heat of adsorption it is reasonable to presume that phenol interacted with the basic polyaromatic rings of the coal. The low molar heat obtained for pyridine adsorption is difficult to explain in that acidic sites typically found in coals such alcohols, pyroles, and thiols should give much larger heats.

\section{Table I}

Proximate and ultimate analyses in welght percent for Primrose low ash anthracite coal (PSOC 870) from the Great Lakes mine in Schuylkill county, Pennisylvania

\section{Proximate Analysis as Recelved}

$\begin{array}{lr}\text { Moisture } & 3.84 \\ \text { Ash } & 2.46 \\ \text { Volatile Matter } & 2.93 \\ \text { Ixed Carbon } & 90.77\end{array}$

\section{U1timate Analysis. Dry Ash Free}

$\begin{array}{lr}\text { Carbon } & 95.54 \\ \text { Hydrogen } & 1.87 \\ \text { Nitrogen } & 0.71 \\ \text { Sulfur } & 0.51 \\ \text { Chlorine } & 0.01 \\ \text { Oxygen (diff.) } & 1.37\end{array}$




\section{Table 2}

Heats of adsorption of test probes on Primrose low ash anthracite (PSOC 870) coal powders and the concentration of sites.

\begin{tabular}{lccc} 
Probe & $\begin{array}{c}-\Delta \mathrm{H}^{\mathrm{ab}} \dagger \\
\mathrm{kcal} / \mathrm{mole}\end{array}$ & $\begin{array}{c}\text { Sites/gram } \\
\times 10^{18}\end{array}$ & $\begin{array}{c}-\Delta \mathrm{H}^{\mathrm{ab}} \ddagger \\
\mathrm{kcal} / \mathrm{mole}\end{array}$ \\
\hline Pyridine \\
2,6 -ditertbuty1 - & $2.4 \pm 0.6$ & 2.4 & - \\
4-tertbutyl. & $1.2 \pm 0.2$ & 2.9 & $6.1 \pm 0.5$
\end{tabular}

Phenol

$\begin{array}{llll}3,5 \text {-ditertbutyl- } & 0.9 \pm 0.2 & 4.2 & 10 \pm 4\end{array}$

$\dagger$ This work

₹ Fowkes et al, Energy \& Fuel.s 3, 97-105 (1989).

\section{Conclusions}

Although we were beset with many problems this quarter, all of the major ones have been overcome. Several weeks were taken to identify that the problems did not lie in the sample preparation and packing in the calorimeter but in the electronics of the instrument. Several more weels were then spent tracking down and correcting all of the problems. In the end however, we obtained an instrument which we have used in other research plo, ucts wherein It has performed flawlessly. The data reported in this report was obtained during the period in which the instrument was operating at much less than 100 o accuracy. As inight be expected, these results do not agree very well with our

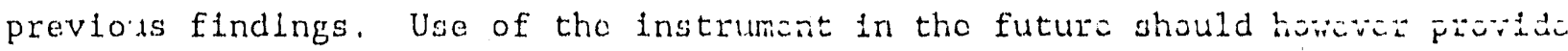
much better results. 

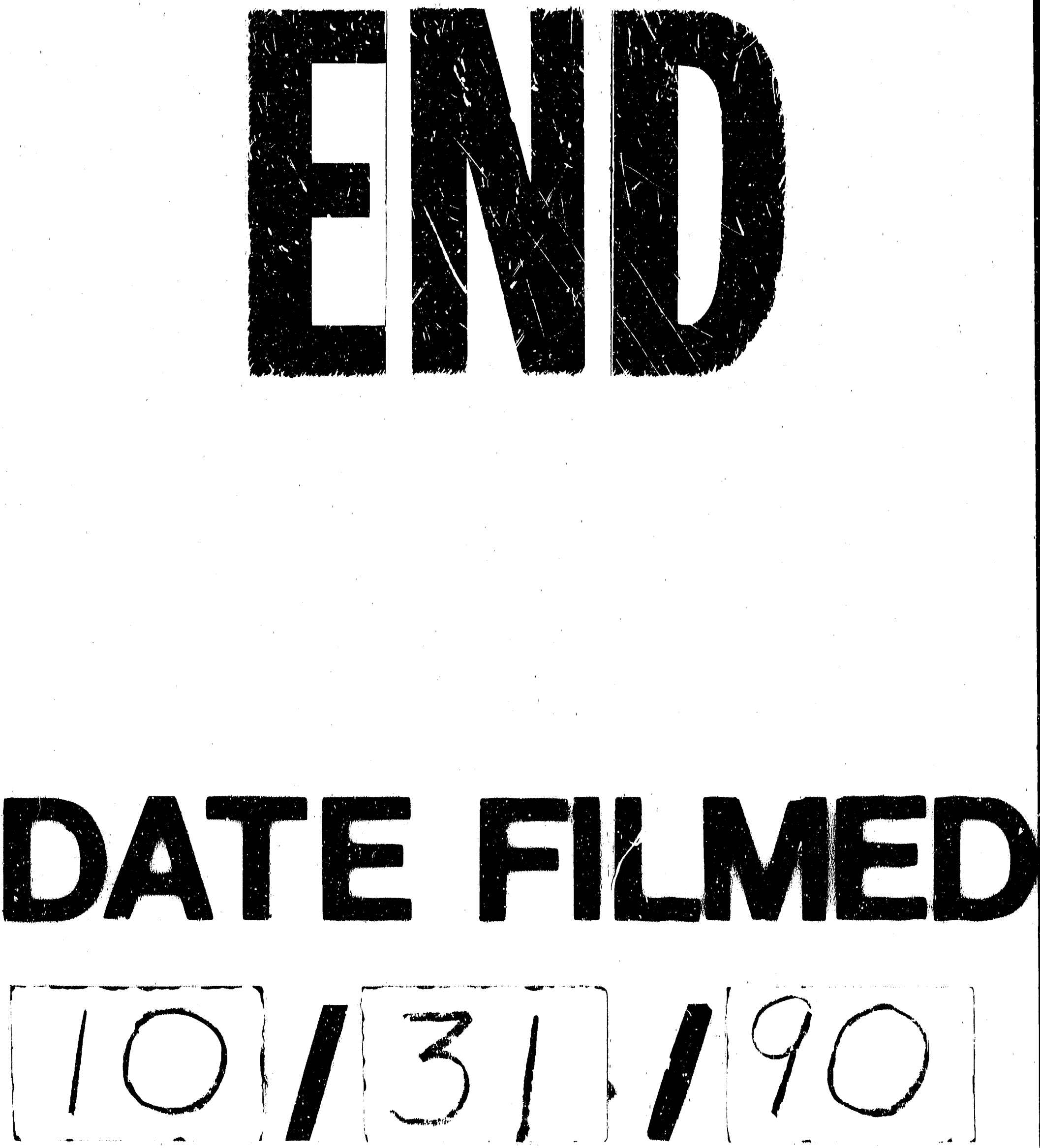
